\title{
Arketipe Ketaksadaran Tokoh Faris dan Inayah dalam Novel Lail wa Qudbhan Karya Najib Al-Kailani
}

\author{
Rahimal Khair \\ Universitas Islam Negeri (UIN) Sunan Kalijaga Yogyakarta \\ rohim.bsa2013@gmail.com
}

\begin{abstract}
This research aims to describe the psychological conflict that can impact the changes of Faris and Inayah attitudes when acting on novel Lail wa Qudbhan by Najib al-Kailani. The approach of this research is the psychology of literature that discusses of the psychology aspects of figures in the work or is called the textual approach. The theory used to study the psychology of figures in this research is Carl Gustav Jung's psychology theory and focused on the archetypes of the character's unconsciousness. The research method used is a qualitative method, documentation technical with descriptive analysis of data analysis. There is also the result of this study found that the cause of the change in attitude of Faris and Inayah figures is their unconscious archetype. Faris's archetype consists of a persona obstinacy, a shadow of killing and copulation, his anima is uncontrolled emotional, a great mother who brings destruction, wise old man who advise and teach patience, and Self want freedom of life and happiness. While Inayah's archetype consists of a persona of a happy wife, a shadow of murder an infidelity, an animus of rational and stubborn thinking, a great mother who loves, wise old man who teaches patience, and Self want freedom and happiness.
\end{abstract}

Keywords: Najib al-Kailani, Lail wa Qudbhan, Carl G. Jung

\begin{abstract}
Abstrak
Penelitian ini bertujuan mendeskripsikan konflik psikologis yang menyebabkan perubahan sikap tokoh Faris dan Inayah dalam bertindak pada novel Lail wa Qudbhan karya Najib al-Kailani. Pendekatan penelitian ini adalah psikologi sastra yang membahas aspek psikologi tokoh dalam karya atau disebut pendekatan tekstual. Teori yang digunakan untuk mengkaji psikologi tokoh dalam penelitian ini adalah teori psikologi Carl Gustav Jung dan berfokus pada arketipe ketaksadaran tokoh. Metode penelitian yang digunakan adalah metode kualitatif, teknik dokumentasi, dan analisis
\end{abstract}


data deskriptif analisis. Ada pun hasil penelitian ini menemukan penyebab perubahan sikap tokoh Faris dan Inayah adalah arketipe ketidaksadaran mereka yang mengarah dua arah yaitu positif dan negatif. Arketipe tokoh Faris terdiri atas persona ketegaran, bayangan membunuh dan bersetubuh, anima emosinal, ibu agung yang membawa kehancuran, orang tua bijak yang menasihati dan mengajarkan kesabaran, dan diri yang menginginkan kebebasan hidup. Sementara arketipe tokoh Inayah terdiri atas persona istri yang bahagia, bayangan membunuh dan perselingkuhan, animus berpikir rasional dan keras kepala, ibu agung mengasihi, orang tua bijak yang mengajarkan kesabaran, dan diri ingin kebebasan dan kebahagiaan.

Kata Kunci: Najib al-Kailani; Lail wa Qudbhan; Carl G. Jung

\section{Pendahuluan}

Karya sastra merupakan produk dari suatu keadaan kejiwaan dan pemikiran pengarang yang berada dalam situasi setengah sadar (subconcious), setelah mendapat bentuk yang jelas dituangkan ke dalam bentuk tertentu secara sadar (consious) dalam bentuk penciptaan karya. ${ }^{1}$ Karya sastra dapat dipahami sebagai hasil komunikasi alam bawah sadar pengarang dengan alam sadarnya untuk menghadirkan banyak imajinasi dan mengelola imajinasi tersebut menjadi imajinasi yang jelas dan berbentuk, setelah imajinasi lebih jelas dan berbentuk dalam alam sadarnya, kemudian imajinasi dituangkan dalam bentuk tulisan yang dapat dibaca oleh orang lain atau pembaca.

Karya sastra sebagaimana diketahui memiliki genre yang beraneka ragam, Rokhmansyah merangkumnya menjadi tiga genre yaitu puisi, prosa, dan drama. Novel menjadi salah satu jenis karya sastra yang digolongkannya dalam genre prosa, novel dapat dipahami sebagai jenis karya sastra yang menceritakan sebuah peristiwa atau pengalaman lahir dan batin tokoh yang dianggap luar biasa dalam kehidupan manusia yang menyebabkan hidup tokoh cerita yang ditampilkan dapat berubah. ${ }^{2}$ Jabra Ibrahim yang dikutip oleh Roger Allen, memberikan catatan pada awalnya novel menggambarkan konflik individu melawan kekuatan yang lebih besar dari dirinya berkembang menggambarkan kehidupan masyarakat serta konflik-konflik di sekitarnya termasuk sisi batiniah mereka. ${ }^{3}$ Dari beberapa pendapat tersebut dapat dipahami bahwa novel memiliki kelebihan yang tidak dimiliki oleh genre sastra yang lain. Novel memiliki ruang

${ }^{1}$ Suwardi Endraswara, Metode Penelitian Psikologi Sastra (Yogyakarta: Medpress, 2008), hal.

7.

2 Alfian Rokhmansyah, Studi dan Pengkajian Sastra (Yogyakarta: Graha Ilmu, 2014), 13.

3 Roger Allen, Pengantar Kajian Novel Arab, trans. oleh Erza (Yogyakarta: Era Baru Pressindo, 2012), hal. 2-3. 
yang lebih panjang dan bebas dalam menceritakan atau mengkreasikan sebuah cerita sehingga pembaca mendapatkan gambaran kisah yang utuh.

Salah satu novel Arab yang menarik dan mengambarkan kelebihan novel ialah novel Lail wa Qudbhan karya dari sastrawan Islam terkenal yang bernama Najib al-Kailani. Ia tercatat telah meraih beberapa penghargaan yang bergengsi dan beberapa karyanya telah diterjemahkan ke beberapa bahasa. ${ }^{4}$ Ia juga dalam hidupnya, pernah beberapa kali jebloskan ke penjara karena urusan pandangan politik, yaitu karena mengikuti perkumpulan Ikhwanul Muslimin yang oposisi terhadap pemerintah. ${ }^{5}$ Najib al-Kailani juga dianggap sebagai sastrawan yang menggunakan karya sastra sebagai sarana untuk berdakwah. ${ }^{6}$ Sehingga hal tersebut yang mempengaruhi al-Kailani dalam karyanya baik dalam karya-karya yang memuat nilai-nilai keislaman maupun perlawanan terhadap ketidakadilan. Najib al-Kailani menggambarkan kisah kehidupan tokoh dengan gamblang disertai dengan berbagai konflik sosial maupun konflik kejiwaan seperti yang dialami oleh kebanyakan orang di dalam penjara. Kemampuan al-Kailani menggambarkan kisah kehidupan penjara dalam novel Lail wa Qudbhan ternyata juga ditopang oleh pengalamannya ketika menulis dan menerbitkan novel tersebut ketika ia masih dalam penjara Qanathir. ${ }^{7}$ Bahkan al-Kailani dipercaya sebagai sastrawan yang membuat karya sastra mempertimbangkan kesesuaian dengan kondisi sosial, politik, agama, dan sisi kesejarahann yang ada. ${ }^{8}$

Najib al-Kailani dalam novel Lail wa Qudbhan, menceritakan kisah beberapa tokoh yang mengalami kehidupan di dalam penjara dan sekitarnya, namun ada dua tokoh yang kemunculannya mendominasi cerita dalam novel tersebut, yaitu Faris seorang narapidana karena membunuh dan Inayah adalah istri kepala penjara. Para tokoh dalam novel menjalani kehidupan penjara penuh dengan konflik dan masalah. Faris sering mengalami penyiksaan yang dilakukan oleh para sipir penjara karena kesalahan kecil namun ia tetap kuat dan terlihat tegar menghadapinya. Sementara Inayah dalam rumah tangganya bersama Abdul Hadi merasa terkekang dan tidak bahagia karena tidak kunjung memiliki anak dan sering diperlakukan tidak adil terutama dalam urusan kebutuhan biologisnya namun ia selalu berusaha terlihat tersenyum dan bahagia. Sementara Inayah digambarkan menderita dan terjadi konflik dalam dirinya karena memiliki suami yang tidak memahami kebutuhannya sebagai seorang perempuan. Ia pun

${ }^{4}$ Abdullah bin Shalah Al-Arini, Al-Ittihah al-Islamy fii A'mal Najib al-Kailany al-Qasasiyyah (Riyadh: Dar Kunuz Isbiliya Linnasyri wa al-Tauzik, 2005), hal. 29.

${ }^{5}$ Al-Arini, hal. 14-15.

${ }^{6}$ Novi Ariyanti, "Kajian Sosiologi Sastra Pada Tokoh Utama dalam Novel al-Rajul alLadri Amana Karya Najib al-Kailani," Arabiyatuna: Jurnal Bahasa Arab Vol. 3. No. 1 (Mei 2019): hal. 3 .

${ }^{7}$ Najib al-Kailani, Tajribati al-D zati fii Qissah al-Islamiyyah (Kairo: Al-Sahoh, 2015), 106.

${ }^{8}$ Nia Hailiyati, "Perbandingan Ideologi Pada Novel ‘Azra’ Jakarta Dengan Imagologie Sejarah G30s-Pki Versi Perpustakaan Nasional," Tsaqofah \& Tarikh 4, no. 1 (Juni 2019): hal. 7887. 
memilih untuk berpura-pura menerima pemberian suaminya sembari tersenyum padahal dalam hatinya tidak demikian dan dalam hatinya ada kebencian yang membara terhadap Abdul Hadi.

Dari gambaran singkat di atas dapat diketahui bahwa tokoh Faris dan Inayah berpura-pura kuat, tegar, bahagia, dan tersenyum dalam menjalani hidup mereka. Kepura-puraan yang dilakukan oleh tokoh Faris dan Inayah tentu didorong oleh tekanan jiwa atau tekanan psikologis terutama alam bawah sadar. Bila dilihat dari pandangan psikologi, maka apa yang dialami oleh dua tokoh tersebut merupakan dorongan-dorongan kejiwaan yang berasal dari alam bawah sadar mereka yang dikenal sebagai arketipe ketaksadaran. Menurut Jung, aspekaspek alam bawah sadar tersebut lah yang akan mempengaruhi persepsi manusia terhadap realitas yang mereka hadapi.

Ada pun arketipe adalah kepingan hidup itu sendiri-citraan yang terhubung secara padu dengan kehidupan melalui sebuah jembatan emosional. Arketipe menjadi hidup hanya ketika kita dengan sabar mencoba menemukan mengapa dan dalam cara apa arketipe tersebut memberikan makna dalam kehidupan seseorang. Jung juga menjelaskan untuk dapat memahami arketipe dari seseorang hendaknya dilakukan dengan mengaitkan arketipe dengan situasi kehidupan secara utuh dari individu yang orang yang bersangkutan. ${ }^{10}$ Namun dalam mengenali arketipe dalam karya sastra dapat dikenali dengan prilaku tokoh atau faktor yang menyebabkan tokoh berprilaku demikian.

Berkaca dari penjelasan Jung di atas, maka tindakan yang dilakukan oleh tokoh Faris dan Inayah dipengaruhi oleh alam bawah sadar mereka dalam bentuk arketipe. Sehingga untuk mengerti perubahan prilaku dan sikap tokoh Faris dan Inayah dalam novel Lail wa Qudbhan tersebut perlu dilakukan kajian yang dapat menjelaskan arketipe yang mempengaruhi psikologis mereka di saat mereka menjalani kehidupan sehari-hari.

Penelitian ini akan menguraikan masalah psikologis tokoh Faris dan Inayah dengan menggunakan pendekatan psikologi sastra, lebih khususnya pendekatan teksual, yang digunakan untuk mengkaji karya sastra terkait aspek psikologis tokoh dalam karya sastra. ${ }^{11}$ Pendekatan tersebut ditopang oleh teori psikologi analitik Carl Gustav Jung terutama pada tataran arketipe ketaksadaran. Adapun rumusan masalah dalam artikel adalah bagaimana arketipe ketaksadaran tokoh Faris dan Inayah dalam novel Lail wa Qudbhan dapat mempengaruhi prilaku mereka ditinjau dari teori psikologi analitik Carl Gustav Jung. Teori

${ }^{9}$ Carl Gustav Jung, Manusia dan Simbol-Simbol: Simbolisme dalam Agama, Mimpi, \& Mitos, trans. oleh Siska Nurrohmah (Yogyakarta: Basabasi, 2018), hal. 8.

${ }^{10}$ Jung, hal. 136-37.

11 Endraswara, Metode Penelitian Psikologi Sastra, 343. Lihat Juga, Suwardi Endraswara, Metodologi Penelitian Sastra: Epistemologi, Model dan Aplikasi (Yogyakarta: Medpress, 2008), hal. 9798. 
psikologi analitik ini peneliti pilih karena teori tersebut sesuai dengan tujuan penelitian dalam artikel ini yaitu menganalisis maksud perubahan prilaku Faris dan Inayah dalam novel Lail wa Qudbhan karya Najib al-Kailani.

Dari beberapa penjelasan di atas, maka penelitian ini perlu dilakukan untuk memberikan salah satu bentuk pemahaman kepada pembaca, di samping hasil penelitian dari peneliti telah menjadikan karya-karya Najib al-Kailani menjadi objek penelitan mereka termasuk novel Lail wa Qudbhan tersebut. Penelitian ini mengkaji novel Lail wa Qudbhan dengan pendekatan atau teori yang berbeda termasuk penelitian ini karena akan dapat menambah sudut pandang dan pemahaman pembaca terhadap novel tersebut. Beberapa penelitian yang sudah dilakukan yaitu karya Muhammad Mahdi Samti dan Samanah Naqwi yang menemukan adanya implikasi sosial dalam novel tersebut yang berterkaitan dengan kebebasan Perempuan, hak mendapatkan pendidikan, kebebasan memilih pasangan dan bercerai. Najib al-Kailani menggambarkan tokoh perempuan yang licik dan jahat namun sangat cantik. ${ }^{12}$

Ada pula penelitian berupa skripsi yang telah membahas novel Lail wa Qudbhan yaitu skripsi yang ditulis oleh Tazkiyyatul Amanah ${ }^{13}$ dan Mukramatun. ${ }^{14}$ Tazkiyyatul dalam skripsinya menggunakan kritik sastra feminis yang berhasil menemukan penindasan terhadap Inayah dan adanya perlawanan yang digambarkan oleh penulis sehingga disimpulkan karya itu termasuk karya yang pro feminis. Penelitian tersebut menitikberatkan pada seberapa feminis Najib alKailani dengan melihat pengambaran tokoh perempuan dalam novel, padahal dalam novel tidak hanya tokoh perempuan yang mengalami penindasan. Sementara Mukramatun menggunakan teori psikologi kepribadian Sigmund Freud menemukan tiga unsur kepribadian yaitu id, ego, dan super ego. Penelitian Mukramatun masih terlalu umum belum mampu melihat konflik psikologis tokoh Faris dan Inayah.

Dari beberapa hasil penelitian di atas, tentu novel Lail wa Qudbhan masih bisa dikaji dengan teori yang lain karena hasil penelitian Samti dan Naqwi memberikan gambaran tentang perempuan yang bertentangan. Di satu sisi Samti dan Naqwi menemukan pembelaan al-Kailani terhadap hak-hak perempuan, namun di sisi lain mereka menjelaskan al-Kailani menjelekkan

12 Muhammad Mahdi Samti dan Samanah Naqwi, "al-Madhamin al-Ijtima'iyyah fi Riwayah Lail wa Qudbhan Li Najib al-Kailani," Majallah Bubus fi al-Lughah al-Arabiyyah wa Adabiha: Nisfu Sanawiyyah 'Alamiyyah Mubkamah li Kulliyyah al-Lughab al-Ajnabiyyah bi Jami'ab Isfahan Volume 7 (Musim Gugur dan Musim Semi H/1433-1434 H 1391): 93-112.

13 Tazkiyyatul Amanah, "Surah 'Inayat Hanim fii al-Riwayah Lail wa Qudbhan Li Najib al-Kailani (Dirasah Naqdiyyah Adabiyyah Nisaiyyah)" (skripsi, UIN Sunan Kalijaga, 2017), http://digilib.uin-suka.ac.id/28755/.

14 Mukramatun, "al-Shira'u al-Nafsi fii Riwayah 'Lail wa Qudbhan' Linajib al-Kailani (Dirasah Shikulujiyyah)" (Skripsi, Banda Aceh, UIN Ar- Raniry, 2018), http://library.arraniry.ac.id. 
perempuan dengan menggambarkan tokoh perempuan dengan watak yang buruk. Gambaran yang bertentang tersebut membuat peneliti melakukan penelitian lanjutan agar pembaca novel Lail wa Qudbhan mendapatkan penjelasan yang memadai terkait prilaku buruk atau citra buruk tokoh perempuan yang ditampilkan dalam novel tersebut. Hal tersebut dapat dijelaskan dengan teori Jung sebagaimana penjelasan sebelumnya, terutama ketika menggunakan teori ini dengan tahapan mencari makna-makna tersembunyi melalui mencari makna dari arketipe yang muncul kemudian faktor-faktor penentu kemunculannya sehingga akan ditemukan makna karya secara utuh. ${ }^{15}$ Oleh sebab itu, penelitian ini mengkaji sisi psikologis tokoh agar bisa menjelaskan fenomena tingkah buruk tokoh dalam novel terutama tokoh Faris dan Inayah yang merupakan tokoh central dalam novel dan terpecahkan mengapa tokoh perempuan dalam novel tergambarkan sebagai perempuan yang buruk dan licik.

Berdasarkan objek penelitian berupa novel Lail wa Qudbhan, maka penelitian ini merupakan penelitian kualitatif, yaitu penelitian yang dilaksanakan dengan membaca, mempelajari, dan membandingkan beberapa rujukan atau bahan bacaan yang berhubungan dengan tema penelitian, kemudian menyimpulkannya. ${ }^{16}$

Teknik pengumpulan data yang digunakan adalah teknik dokumentasi. ${ }^{17}$ Teknik ini dijalankan dengan cara menelusuri atau membaca novel Lail wa Qudbhan berulang-ulang dengan teliti sampai ditemukan data-data berupa kutipan-kutipan yang berpotensi mengambarkan bentuk-bentuk arketipe tokoh Faris dan Inayah dalam novel tersebut.

Metode analisis data yang digunakan dalam menganalisis novel Lail wa Qudbhan adalah metode deskriptif analisis, ${ }^{18}$ yang dilakukan mendeskripsikan kutipan-kutipan yang mengambarkan arketipe ketaksadaran tokoh yang ditemukan atau didokumentasikan sebelumnya dengan berpedoman pada teori psikologi analitik Carl Gustav Jung. selanjutnya arketipe ketaksadaran tokoh dianalisis untuk menemukan makna dan faktor-faktor penentu kemunculannya. Dengan begitu hasil pembahasannya akan memberikan pemaknaan yang lebih mendalam dan utuh kepada pembaca dan dapat menjawab permasalahan psikologis tokoh yang berusaha dijelaskan melalui penelitian ini. Sehingga akan tergambarkan bagaimana arketipe ketidaksadaran tokoh Faris dan Inayah mempengaruhi perilaku dan tindakan mereka.

${ }^{15}$ Carl Gustav Jung, The Spirit in Man, Art, and Literature: Betapa Dabsyatnya Spirit Manusia, trans. oleh Cep KM Subhan (Yogyakarta: IRCisoD, 2019), hal. 125.

${ }^{16}$ Nyoman Kutha Ratna, Teori, Metode, dan Teknik Penelitian Sastra (Yogyakarta: Pustaka Pelajar, 2015), hal. 47-48.

17 Mahi M. Hikmat, Metode Penelitian: Dalam Perspektif Ilmu Komunikasi dan Sastra (Yogyakarta: Graha Ilmu, 2011), hal. 83.

${ }^{18}$ Ratna, Teori, Metode, dan Teknik Penelitian Sastra, hal. 53. 


\section{Hasil dan Pembahasan}

\section{Sinopsis Novel Lail wa Qudbhan}

Novel Lail wa Qudbhan menceritakan kisah kehidupan di penjara dan sekitar penjara terutama komplek perumahan sekitar penjara yaitu rumah kepala penjara. Cerita dalam novel ini di dominasi oleh dua tokoh yaitu Faris dan Inayah. Faris merupakan seorang mahasiswa teknik elektro yang terpaksa berenti karena ia harus menjalani hukuman penjara. Ia memperoleh hukuman penjara karena kejahatan pembunuhan yang ia lakukan terhadap orang yang telah membunuh ayahnya. Kejahatan pembunuhan tersebutlah yang membuatnya kena hukuman lima belas tahun penjara. Di dalam penjara ia memiliki teman satu sel yang selalu bersama dengannya yang bernama Abdul Hamid, dan Syeikh Salman. Faris selama di dalam penjara banyak mengalami penyiksaan dari sipir penjara yang bernama Syalqomi. Selain itu, Faris juga mendapatkan penghinaan dan penyiksaan dari kepala penjara yang tidak berperi kemanusiaan. Walau pun kerapkali mengalami penyiksaan dari sipir penjara, Faris berkomitmen untuk menyelesaikan hukuman kurungan penjaranya dengan baik tanpa melakukan pemberontakan dan membuat konflik. Namun pada akhirnya ia kehilangan nyawanya di dalam penjara akibat melakukan kesalahan yang sangat fatal. Ia melakukan perzinahan dengan Inayah.

Sementara Inayah merupakan istri kepala penjara. Ia berasal dari keluarga terhormat dan ayahnya seorang hakim. Ia menikah dengan Abdul Hadi atas paksaan orang tuanya dan keluarganya. Pernikahannnya dengan Abdul Hadi tidak membuat Inayah bahagia karena ia menjadi terkekang dan kesepian. Ia tidak bisa memiliki anak karena suaminya mengidap penyakit lever, hipertensi dan gula darah. Selain itu, suaminya juga terlalu mengekang dan tidak memberikan kebebasan kepadanya bahkan ketika Inayah menginginkan sesuatu dan memberikan pendapatnya tidak pernah dihiraukan. Rumah tangga Inayah seringkali mengalami konflik yang disebabkan oleh masalah yang sederhana. Setelah sepuluh tahun menjallani pernikahan Inayah semakin tidak tahan dan ingin sekali Abdul Hadi cepet meninggal karena pernyakit yang dialaminya. Kematian Abdul Hadi yang tak kunjung dating membuat Inayah berencana untuk membunuhnya tapi setelah ia berpikir panjang ia pun memutuskan tidak membunuh suaminya dengan tangannya. Ia pun memutuskan untuk melakukan perzinahan dengan dengan Faris agar ia bisa terbebas dari Abdul Hadi.

Perzinahan yang dilakukan oleh Faris dan Inayah sengaja dibiarkan terbongkar oleh Inayah agar suaminya mengetahuinya sehingga ia diceraikan dan dan suaminya lepas kontrol. Abdul Hadi pun memerintahkan Syalqomi untuk meracuni Faris dan memerintahkan dokter penjara untuk memanipulasi laporan kematian Faris. Namun dokter tidak mengikuti perintah untuk memanipulasinya hingga semua kejahatan Abdul Hadi dan Syalqomi pun terbongkar dan mereka dihukum penjara atas semua kejahatan. 


\section{Arketipe Ketaksadaran Faris dan Inayah dalam Novel Lail wa Qudbhan Karya Najib al-Kailani}

Pada novel Lail wa Qudbhan Karya Najib al-Kailani tersebut terdapat dua tokoh yang dimunculkan dengan dominan yaitu tokoh Faris dan Inayah. Faris merupakan tokoh yang awalnya baik dan berniat menjalankan kehidupan sebagai narapidana dengan baik hingga dibebaskan dari hukumannya, namun pada akhirnya ia tidak dapat menyelesaikan hukuman kurungannya tersebut karena sebuah kesalahan yang dilakukannya. Kesalahan yang diperbuat oleh Faris tidak terlepas dari pengaruh alam taksadarnya berupa arketipe. Begitu pula dengan Inayah yang pada awalnya tidak mempermasalahkan pernikahan paksa yang dijalani bersama Abdul Hadi berubah menjadi perlawanan dan ia ingin segera terbebas dari cengkraman Abdul Hadi. Sebagaimana Faris, perubahan sikap Inayah dalam menjalani hidupnya tentu dipengaruhi pula oleh alam taksadarnya yang kemudian bisa dijabarkan sebagai arketipe ketidaksadaran. Adapun untuk memperjelas arketipe ketidaksadaran tokoh Faris dan Inayah dijabarkan sebagai berikut:

\section{Persona Ketegaran Faris dan Kebahagian Inayah}

Faris menunjukkan persona atau wajah ketegaran kepada orang sekitarnya terutama kepada kepala penjara. Ketegaran yang ditampilkan itu adalah wajah palsu karena sebenarnya ada kepedihan yang dirasakannya dan ada tangisan dalam hatinya. Sementara Inayah selalu menampakkan persona atau wajah bahagia di depan suaminya dan orang sekitarnya padahal di dalam hatinya tidak ada kebahagiaan. Persona adalah kepribadian yang ditampilkan kepada publik, aspek-aspek kepribadian yang ditunjukkan kepada dunia, atau pendapat publik mengenai diri individu sebagai lawan dari kepribadian privat yang berada di balik wajah sosial. ${ }^{19}$ Persona dapat dipahami sebagai wajah yang dipakai oleh seseorang untuk menghadapi publik atau dunia luar. ${ }^{20}$

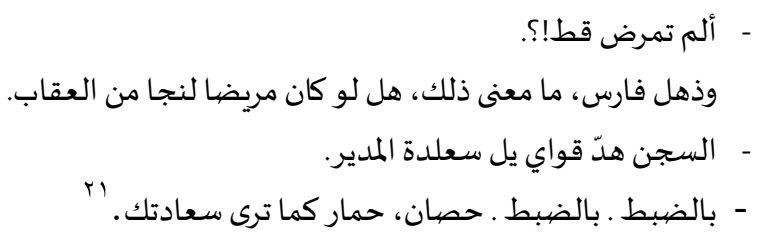

Kutipan di atas merupakan salah satu bentuk ketegaran Faris dalam menjalani hidupnya yang pedih di dalam penjara, walau pun tubuhnya gemetar ketakutan namun ia berpura-pura tenang dan tegar menjawab pertanyaan kepala penjara. Keluhan akan kepedihan dan ketersiksaan di dalam penjara tidak ia

\footnotetext{
${ }^{19}$ Alwisol Alwisol, Psikologi Kepribadian (Malang: UMM Press, 2009), hal. 43.

${ }^{20}$ Jung, Manusia dan Simbol-Simbol: Simbolisme dalam Agama, Mimpi, \& Mitos, hal. 44.

${ }^{21}$ Najib al-Kailani, Lail wa Qudbhan (Kairo: Al-Sahoh, 2013), hal. 27-28.
} 
tampilkan. Faris menggunakan persona ketegaran dalam kesehariannya di penjara saat berinteraksi untuk menutupi kepedihan di dalam hatinya.

Adapun Inayah yang tidak bahagia dalam rumah tangganya harus purapura bahagia dan mencintai suaminya. Padahal di dalam hatinya ia sangat menderita dan membenci suaminya.

$$
\begin{aligned}
& \text { - لقد قررت أن أشترى لك عقدا ذهبيا مطعما بالجواهر، }
\end{aligned}
$$

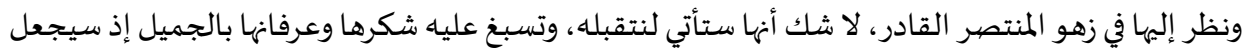

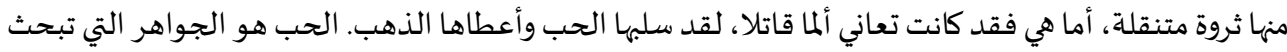

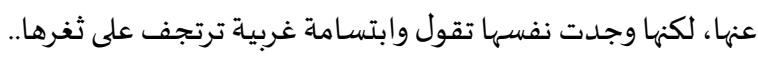

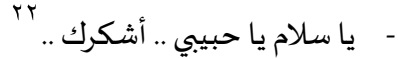

Pada kutipan di atas dapat dilihat tokoh Inayah berpura-pura senang dengan tersenyum ketika suaminya akan memberikannya perhiasan, padahal di dalam hatinya ia merasa kesakitan karena ia telah kehilangan mimpinya dan cintanya. Pura-pura bahagia merupakan persona yang Inayah gunakan saat berhadapan dengan suaminya dan orang lain.

Dari beberapa penjelasan di atas dapat dipahami bahwa Faris dan Inayah berpura-pura terlihat kuat, tegar, senyum, dan bahagia ketika berhadapan dengan orang-orang di sekitar mereka terutama orang terdekat agar mereka tidak dilecehkan dan tidak diremehkan oleh mereka. Persona juga ditampilkan agar tidak mendatangkan khawatiran dari orang terdekatnya dan menjaga perasaan mereka. Arketipe persona yang ditampilkan oleh Faris dan Inayah digunakan untuk tetap kuat dan survive dalam menjalani kehidupan mereka atau tetap bersikap positif serta berjalan pada norma-norma yang seharusnya. Arketipe persona yang mereka tampilkan ini juga agar mereka bisa menahan penderitaan dan kepedihan yang mereka alami karena adanya dorongan dari orang dekat mereka berupa senyuman dan kata-kata yang menguatkan mereka.

\section{Bayangan Faris dan Inayah Membunuh dan Perzinahan}

Faris memiliki sisi yang negatif yang dapat digolongkan dalam bentuk bayangan berupa bisikan untuk melakukan pembunuhan terhadap orang yang telah membunuh ayahnya dan melakukan persetubuhan bersama Inayah. Sebagaimana diketahui bahwa bayangan adalah arketipe yang merujuk atau memiliki kecenderungan kepada kegelapan dan represi yang menampilkan kualitas-kualitas yang tidak diakui keberadaannya serta berusaha disembunyikan dari diri sendiri dan orang lain. ${ }^{23}$ Arketipe ini dapat disebut sabagai sifat kebinatangan yang lebih menggunakan insting di setiap kali melangkah, dan berpijak. Sebagai arketipe, bayangan melahirkan dalam diri kita konsepsi tentang

22 al-Kailani, hal. 17-18.

${ }^{23}$ Jess Feist, Gregory J. Feist, dan Tomi-Ann Roberts, Teori Kepribadian, trans. oleh R. A. Hadwitia Dewi Pertiwi, 8 ed., vol. 1 (Jakarta: Salemba Humanika, 2017), hal. 118. 
dosa asal, bila bayangan diproyeksikan keluar maka ia menjadi seperti iblis atau musuh. Juga mengakibatkan munculnya pikiran-pikiran, perasaan-perasaan, tindakan-tindakan yang tidak menyenangkan dan patut dicela oleh masyarakat dalam kesadaran dan tingkah laku. ${ }^{24}$

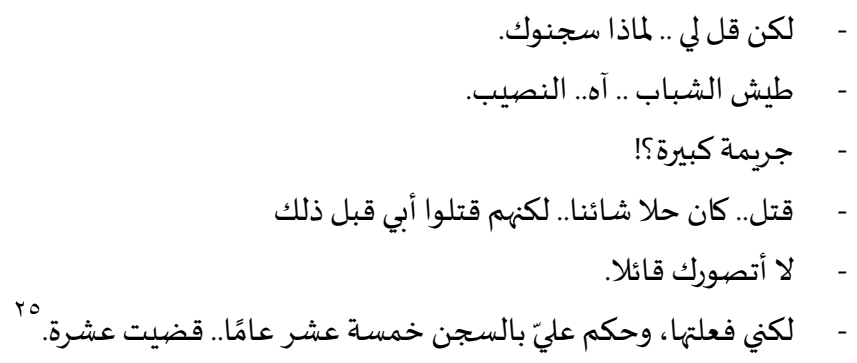

Pada kutipan di atas, Faris memberitahukan Inayah alasan ia dihukum penjara yaitu karena telah melakukan pembunuhan terhadap orang yang telah membunuh ayahnya. Kejahatan seperti itu termasuk sisi buruk atau bayangan yang telah dilakukan oleh Faris dalam hidupnya. Kejahatan pembunuhan tersebut tidak terlepas dari dorongan-dorongan atau bisikan buruk yang yang berasal dari ibunya yang menyuruh balas dendam dan balas dendam yang demikian telah tertanam dalam alam tak sadarnya.

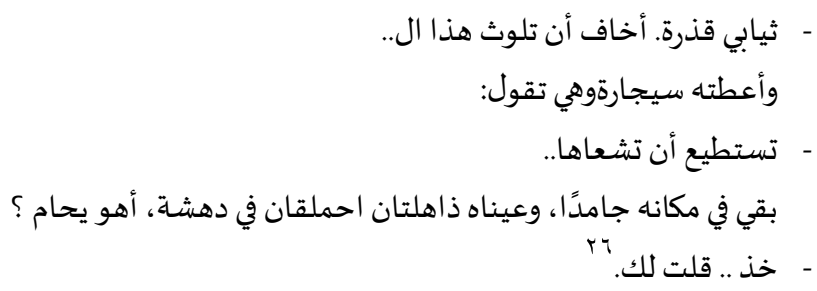

Kutipan di atas merupakan kutipan yang menggambarkan Faris tidak mampu menolak permintaan dan ajakan Inayah hingga terjadilah persetubuhan antara Faris dan Inayah. Selain itu, perselingkuhan mereka terjadi karena ketidakmampuan Faris menolak hubungan badan yang terjadi karena Faris memiliki hasrat yang tidak mampu ditahan dan dilawannya hingga ia melakukan hubungan intim tersebut dengan Inayah yang merupakan istri kepala penjara yang sangat ia takuti.

Adapun bentuk bayangan yang mempengaruhi Inayah adalah dorongan untuk membunuh Abdul Hadi yang telah membuatnya menderita sekian lama yang terus-menerus ia rasakan dan pendam. Bayangan yang muncul dari alam bawah sadar Inayah juga mendorong Inayah untuk melakukan persetubuhan

${ }^{24}$ Calvin S. Hall dan Gardner Lindzey, Psikologi Kepribadian 1: Teori-Teori Psikodinamik (Klinis), ed. oleh A. Supratik (Yogyakarta: Kanisius, 2005), hal. 55.

25 al-Kailani, Lail wa Qudbhan, hal. 43.

26 al-Kailani, hal. 95. 
bersama Faris disebabkan hasratnya yang tidak pernah dipenuhi oleh Abdul Hadi dan perilaku kejam Abdul Hadi pada Inayah.

$$
\begin{aligned}
& \text { - هي لم تعد تستطيع الانتظار، ويبدو أن السماء ليس لديها حل حاسم لمشكلتها .. إنها تستغفر الله قد يكون الحل }
\end{aligned}
$$

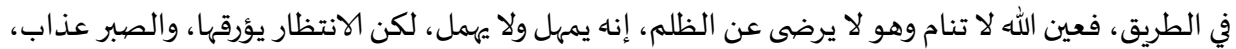

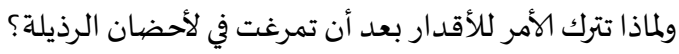

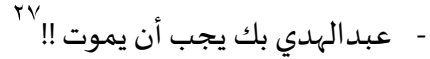

Pada kutipan di atas pengarang menggambarkan bagaimana Inayah menunggu kematian suaminya, ia berharap suaminya cepat mati. Hingga Inayah tidak sabar lagi menunggu kematian Abdul Hadi sesuai dengan hukum atau ganjaran dari Allah atas kedzaliman Abdul Hadi, ia bahkan ingin membunuh Abdul Hadi dengan caranya sendiri. Keinginan tersebut tidak mampu ia jalankan namun ia memilih membunuh Abdul Hadi bukan dengan tangannya, melainkan dengan cara yang tidak diduga hingga Abdul Hadi mati mendadak. Pikiran itulah yang berkembang di alam bawah sadar Inayah .

$$
\begin{aligned}
& \text { - وانبثق من داخلها نداء شيطاني يصرخ: ((تريدين رجلًا)) ارتجف جسدها كله، وحجبت الضوء عن عينها سحابة }
\end{aligned}
$$

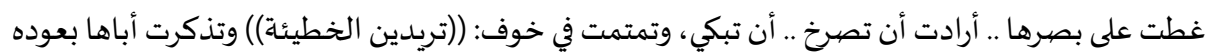

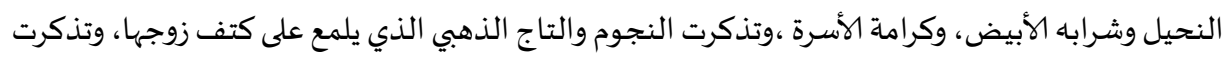

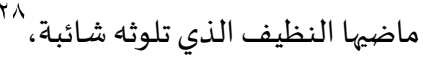

Kutipan di atas menggambarkan Inayah kerap kali mendapat bisikan buruk dari dalam dirinya. Pada kutipan tersebut bayangannya menghendaki Inayah untuk berselingkuh dengan laki-laki lain karena sang suami sudah tidak mampu memberikan Inayah kepuasan seksual. Bisikan dari dalam dirinya itu membisiki Inayah bahwa ia membutuhkan laki-laki untuk memuaskannya hingga ia melakukan perzinahan dengan Faris.

Dari beberapa kutipan dan penjelasan di atas, arketipe bayangan ini lah yang membuat tokoh Faris dan Inayah melakukan hal-hal yang tercela dan melanggar norma yang berlaku sehingga menyebabkan mereka dikucilkan. Arketipe ini membuat mereka berani dan nekat melakukan kejahatan yang awalnya tidak akan mereka lakukan, namun karena dorongan-dorongan dari alam bawah sadar dalam bentuk arketipe ini mereka melakukannya. Arketipe ini menjadi salah satu pendorong perubahan prilaku buruk yang dilakukan oleh Faris dan Inayah.

\footnotetext{
27 al-Kailani, hal. 136.

28 al-Kailani, hal 88.
} 


\section{Anima Faris Tampak Emosional dan Animus Inayah Tampak Rasional}

Faris sebagai lelaki merasa sedih tanpa tahu penyebabnya dan tanpa sadar merasa iba melihat orang lain di sekitarnya yang tersakiti dan terhina akibat perlakuan para penjara penjara. Bahkan Faris bisa menangis karena hal kecil yang menyakiti perasaannya. Sikap Faris tersebut dalam teori Jung diyakini sebagai Anima. Dimana anima adalah representasi psikis dari minoritas gen perempuan yang ada di dalam tubuh laki-laki. ${ }^{29}$ Anima menunjukkan dorongandorongan atau suasana hati yang tidak logis pada diri laki-laki sehingga laki-laki tersebut akan mengalami suasana-suasana atau keadaan-keadaan yang tidak diketahui penyebabnya. ${ }^{30}$ Aspek anima ini akan coba disembunyikan oleh lakilaki karena aspek ini pada dasarnya merupakan sosok yang inferior dibandingkan sifat-sifat yang lain dalam dirinya. ${ }^{31}$

$$
\begin{aligned}
& \text { - - ((أنت تبكي يا فارس ؟؟)). }
\end{aligned}
$$

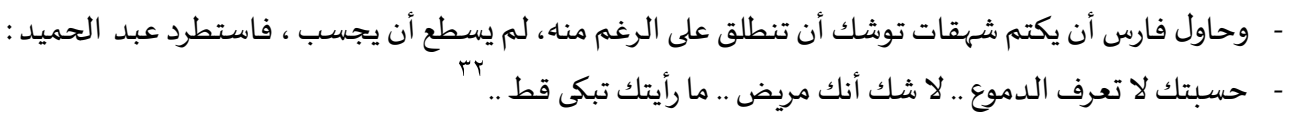

Pada kutipan di atas digambarkan Faris merupakan laki-laki yang cepat terbawa suasana perasaan. Ia bisa menangis karena hal yang kecil. Menangis adalah salah satu bentuk anima dari seorang laki-laki yang terus-menerus dihindari dan disembunyikan oleh laki-laki. Sebagaimana Abdul Hamid baru pertama kali melihat Faris menangis selama sepulu tahun mereka menjalani hidup di penjara.

Sedangkan Inayah sebagai perempuan tentu ia lebih cenderung menggunakan emosi namun tidak menutup kemungkinan ada arketipe animus dalam diri Inayah. Arketipe Animus Inayah dapat kita lihat dari cara Inayah berbicara pada suaminya, ia sering mengungkapkan pendapat yang rasional dan sesuai dengan kenyataan walaupun dengan menyindir suaminya. Animus dari Inayah juga dapat kita lihat ketika Inayah membuat rencana untuk memperoleh kebebasannya dan cara menjalankannya. Animus mampu mempengaruhi proses berpikir seorang wanita, yang sebenarnya tidak dimiliki oleh seorang wanita sehingga pendapat wanita dipandang tidak logis. Padahal ada banyak pendapat wanita yang valid dan objektif. ${ }^{33}$ Sehingga tidak heran bila seorang perempuan akan menjadi keras kepala dan gemar membuat pendapat-pendapat yang tidak lazim atau menyimpang dari ketentuan. ${ }^{34}$

${ }^{29}$ Carl Gustav Jung, Psikologi dan Agama, trans. oleh Afthonul Afif (Yogyakarta: IRCisoD, 2017), hal. 55.

\footnotetext{
${ }^{30}$ Jung, hal. 55-56.

31 Jung, Manusia dan Simbol-Simbol: Simbolisme dalam Agama, Mimpi, \& Mitos, hal. 23-24.

32 al-Kailani, Lail wa Qudbhan, hal. 3-4.

${ }^{33}$ Feist, Feist, dan Roberts, Teori Kepribadian, hal. 1:119.

${ }^{34}$ Jung, Psikologi dan Agama, hal. 56.
} 


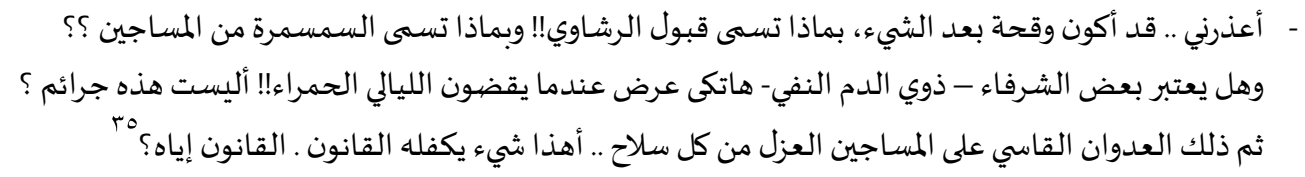

Kutipan di atas merupakan penggalan perdebatan Inayah dan Abdul Hadi, ia mempertanyakan kenapa banyak orang yang seharusnya bersalah seperti orang yang mengurangi jatah makanan narapidana tidak digolongkan kejahatan dan apakah perbuatan itu sesuai dengan hukum. Inayah sangat berani mengajukan pertanyaan tersebut sekaligus menyindir suaminya. Keberanian Inayah mengemukakan pertanyaan dan pendapatnya merupakan salah satu bentuk animus dari Inayah.

Arketipe anima yang muncul dalam gambaran prilaku tokoh Faris dalam novel berupa tangisan yang baru disaksikan oleh temanya setelah sepuluh tahun Faris dihukum penjara ini menggambarkan bahwa sisi emosialnya Faris sudah sulit kontrol. Anima yang sulit dikontrol ini menyebabkan Faris menjadi lebih gampang mengambil keputusan di waktu mendesak terutama ketika ia bertemu dengan Inayah. Sehingga anima ini juga menjadi pendorong perubahan prilaku menyimpang yang dilakukan oleh Inayah. Sementara animus yang muncul pada gambaran perilaku tokoh Inayah berupa betapa rasional pikiran yang ia keluarkan menjadikan ia semakin membenarkan perlawanannya terhadap suaminya. Pembenaran-pembenaran tersebutlah yang membuat ia semakin nekat melakukan perzinahan dengan Faris di samping adanya arketipe bayangan berupa bisikan nafsunya.

\section{Ibu Agung Faris Mendorong pada Kehancuran dan Ibu Agung Inayah Mendorong Mengasihi.}

Dalam novel Lail wa Qudbhan Faris ditampilkan memiliki ibu yang digambarkan sebagai ibu yang konservatif dan mendorongnya menuju kehancuran. Sang ibu mendorong Faris membunuh orang yang telah membunuh suaminya atau ayahnya Faris. Sementara di sisi Inayah sang ibu digambarkan sebagai ibu yang perhatian, pengertian, dan sayang pada anaknya. Hal demikian sesuai dengan konsep arketipe ibu agung yang dirumuskan oleh Jung yang mengatakan bahwa Arketipe ibu agung menampilkan dua dorongan yang berlawanan tersebut dipahami di satu sisi ia menampilkan dorongan untuk kesuburan dan pengasuhan serta di sisi yang lain, ia mendorong pada kekuatan untuk menghancurkan. ${ }^{36}$ Arketipe ibu Agung ini selalu dikaitkan dengan perasaan positif dan negatif. Pada sisi positifnya digambarkan sebagai orang dengan kehangatan, pandai memasak, sangat ramah, dan menyenangkan,

\footnotetext{
35 al-Kailani, Lail wa Qudbhan, hal. 130.

${ }^{36}$ Feist, Feist, dan Roberts, Teori Kepribadian, hal. 1:120.
} 
sedangkan sisi negatifnya berupa memiliki otoritas tak terbantahkan, menakutkan dan tak terduga. ${ }^{37}$

$$
\text { - لقد كرهت كل شيء .. كرهت أبي الذي قتله أعداونا .. وكرهت أمي التي دفعتني إلى الثأر حتى أنا كرهت نفسي .. }
$$

Kutipan tersebut menggambarkan ibunya Faris membawa pengaruh negatif pada Faris yaitu menuntut Faris membalas kematian sang ayah. Sehingga ibunya dapat digolongkan menjadi ibu agung yang membawa kehancuran bagi Faris. Karena pengaruh dan tuntutan ibunya tersebutlah Faris harus menjalani hukuman di penjara selama 15 tahun.

Sementara di sisi Inayah sang ibu digambarkan sebagai ibu yang perhatian, pengertian, dan sayang pada anaknya.

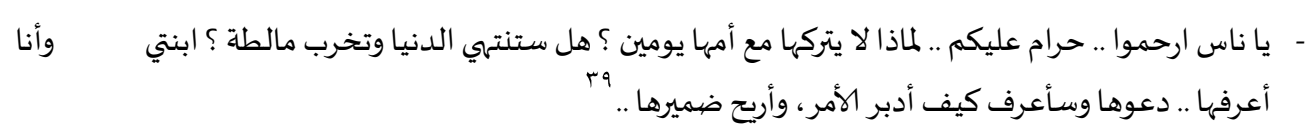

Pada kutipan di atas ibunya Inayah membela Inayah dan berusaha mendekati dan mengetahui permasalahan yang dihadapi Inayah dengan pendekatan kasih sayang. Tindakan sang ibu yang demikian memberikan pengarug positif yang masuk ke dalam alam bawah sadar Inayah berupa ibu Agung yang membangun kekuatan.

Arketipe Ibu Agung pada tokoh Faris memberikan pengaruh buruk padanya, sehingga memperkuat dorongan bayangannya untuk melakukan pembalasan dendam atas kematian orang tuanya. Sementara pada tokoh Inayah, ibu agung memberikan pengaruh positif agar Inayah lebih bisa mengontrol emosinya dan menyadari kewajibannya sebagai seorang istri. Arketipe ibu agung tampil lebih mendengarkan, menemani dan menyayangi Inayah. Hal tersebutlah salah satu faktor yang membuat Inayah kembali ke rumah suaminya dan melaksanakan tugasnya sebagai seorang istri.

\section{Orang Tua Bijak Faris dan Inayah Mengajarkan Kesabaran dan Kebajikan}

Tokoh yang peneliti temukan sebagai tokoh yang sering memberikan nasihat kepada Faris di satu sisi dan Inayah di sisi lain yaitu Abdul Hamid dan ayah Inayah karena mereka kerapkali memberikan nasihat-nasihat kebajikan. Kehadiran dua tokoh ini sesuai dengan yang dipahami sebagai orang tua bijak

\footnotetext{
${ }^{37}$ Carl Gustav Jung, Memories, Dreams, Reflections: Memori, Mimpi, Refleksi, trans. oleh Apri Danarto dan Ekandari Sulistyaningsih (Yogyakarta: Jendela, 2003), hal. 65-67.

38 al-Kailani, Lail wa Qudbhan, hal. 5.

${ }^{39}$ al-Kailani, hal. 60.
} 
yang mempengaruhi pada sisi pengetahuan dan kerohanian seorang individu. Arketipe ini mengajarkan dan mempengaruhi untuk memahami dan menjalankan hidup dengan bijak dan penuh pertimbangan sesuai dengan ajaran agama atau kepercayaan yang diyakini oleh seseorang. ${ }^{40}$

Abdul Hamid adalah teman dekat Faris yang jauh lebih tua, ia sering menegur dan menasihati serta menghibur Faris di saat terpuruk.

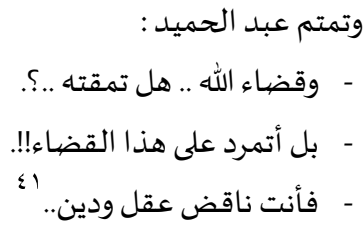

Dari kutipan di atas dapat dilihat Abdul Hamid mencoba menasihati Faris agar ia menerima ketentuan Allah. Akibat nasihat-nasihat dan ajaran dari Abdul Hamid lah Faris pun lebih memilih menghindari konflik dan ingin menjalani hukuman dengan baik serta agar bisa keluar dari penjara setelah masa hukumannya habis.

$$
\begin{aligned}
& \text {... ولم يقف عبد الحميد مكتوف الأيدي، إنها يعرف النتيجة لكي تعيش هانئًا في السجن.. يجب أن تكون ذليلًا .. }
\end{aligned}
$$

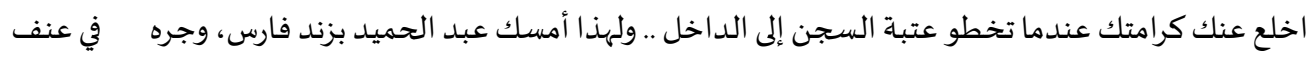

$$
\begin{aligned}
& \text { لعله يوقظه .. وقال وهو يدفعو إلى الأمام : } \\
& \text { \& }
\end{aligned}
$$

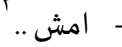

Kutipan ini semakin memperjelas perkataan tokoh Abdul Hamid sebagai gambaran orang tua bijak dalam kehidupan Faris. Ia selalu memperhatikan Faris, membantu saat dalam masalah, dan mendorong Faris untuk berbuat yang benar. Sebagaimana di atas ia melihat Faris dalam keadaan emosi kepada Syalqomi sehingga sebagai orang yang tahu cara bertahan hidup di dunia yang keras ia menggiring Faris untuk menjauh dari Syalqomi agar tidak terjadi keributan.

Sedangkan di pihak Inayah kehadiran sang ayah yang memberikannya nasihat dapat dianggap sebagai wise old man bagi Inayah.

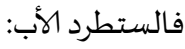

$$
\begin{aligned}
& \text { - المال والبنون زينة الحياة الدنيا .. والمال كثير ، وغدًا يكثر الأولاد، قالت محتدة: } \\
& \text { - لكنه عقيم. هوالعقيم. ولن ينجب. مستحيل. }
\end{aligned}
$$

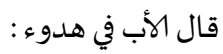

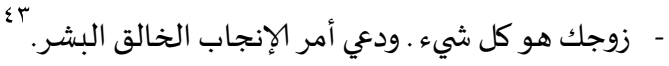

\footnotetext{
${ }^{40}$ Jung, Memories, Dreams, Reflections: Memori, Mimpi, Refleksi, 70-71.

41 al-Kailani, Lail wa Qudbhan, hal. 6.

42 al-Kailani, hal. 7.

43 al-Kailani, hal. 78 .
} 
Pada kutipan di atas dapat dilihat tokoh ayah mencoba menasihati Inayah bahwa harta dan anak merupakan perhiasan dunia. Ia menasihati Inayah bahwa Abdul Hadi merupakan segalanya bagi Inayah walaupun ia tidak memberikan anak pada Inayah dikarenakan Abdul Hadi kena penyakit lever dan dianggap mandul.

$$
\text { - آه .. يجب أن تفهي أن الطلاق جريمة .. كما أرجو ألا تخطر هذه الكلمة على بالك مطلقا .. إن مجرد تلفظى بها }
$$

Kutipan ini merupakan nasihat sang ayah tentang betapa jahatnya sebuah perceraian. Nasihat dari ayah tersebut lah yang membuat Inayah mau kembali ke rumah Abdul Hadi dan menjalani tugasnya sebagai istri kembali. Nasihat itu juga membuat Inayah tidak memilih jalan menggugat cerai suaminya untuk terbebas dari penderitaannya.

Arketipe orang tua bijak didapatkan oleh Faris dalam novel berasal dari Abdul Hamid. Abdul Hamid memberikan nasihat agar Faris lebih hati-hati dan bersabar dalam menjalani kehidupannya di penjara. Nasihat dari Abdul Hamid tersebut yang mempengaruhinya memantapkan niat tidak melakukan perlawanan agar bisa keluar penjara dengan selamat. Sementara pada sisi Inayah kehadiran ayahnya yang menasihatinya agar mempertahankan pernikahan dan tidak melalkukan perceraian adalah sumber orang tua bijak.

\section{Diri Tokoh Faris dan Inayah Kebebasan dan Kebahagiaan Hidup}

Dalam novel ini, arketipe "diri" atau realisasi diri tokoh Faris dan Inayah yang peneliti temukan adalah mereka sama-sama menginginkan kebebasan dan kebahagian dalam hidup mereka ke depannya. Jung menggunakan istilah diri "self" untuk menggambarkan totalitas manusia, yaitu gabungan dari isi kesadaran dan ketaksadaran manusia. ${ }^{45}$ Diri berupa kebahagiaan dan kebebasan yang demikianlah yang sesuai dengan konsep diri yang ditawarkan oleh Jung, yaitu diri dipahami sebagai kekuatan pengatur yang tampak seperti inti atom dari sistem psikis yang bertindak sebagai pencipta, penyusun, atau sumber dari citraancitraan yang ada di dalam mimpi. ${ }^{46}$

$$
\begin{aligned}
& \text { لو تحققت الأماني فلسوف يفرج فارس بعد قضاء ثلاثة أرباع المدة أي بعد سنة واحدة وثلاثة شهور، هذا إذا }
\end{aligned}
$$

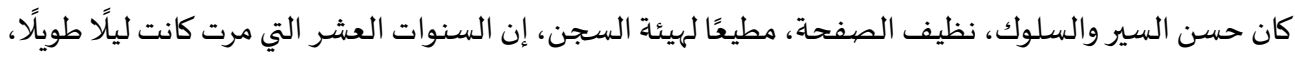

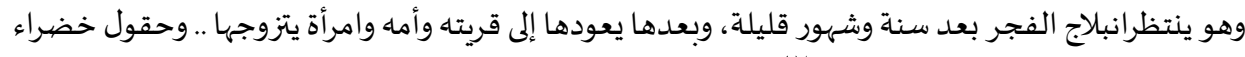

$$
\begin{aligned}
& \text { وحياء حلوة شهية حرمته الأقدار منها .. وأ }
\end{aligned}
$$

\footnotetext{
${ }^{44}$ al-Kailani, hal. 80.

45 Jung, Psikologi dan Agama, hal. 171.

${ }_{46}^{46}$ Jung, Manusia dan Simbol-Simbol: Simbolisme dalam Agama, Mimpi, \& Mitos, hal. 235.

${ }^{47}$ al-Kailani, Lail wa Qudbhan, hal. 69-70.
} 
Kutipan tersebut menggambarkan tokoh Faris ingin bebas dan menjalani sisa hukuman penjara tanpa membuat masalah. Sehingga ketika Abdurradli mengajaknya untuk membunuh Syalqomi ia menolaknya. Jika ia melakukannya ia akan mendapatkan hukuman yang berat dan menyebabkan hukumannya bertambah atau bahkan dijatuhi hukuman mati..

$$
\begin{aligned}
& \text { لا أدري .. لم أعد أفكر ذلك.. إن عمل الههار وألرق الليل والأغلال التي تقيد روحي تنسينى النظر في مثل هذه }
\end{aligned}
$$

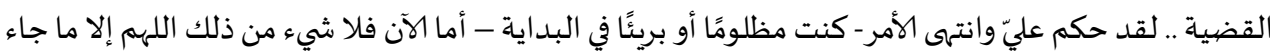

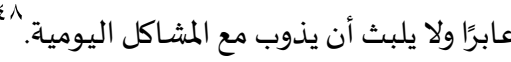

Kutipan di atas jawaban Faris kepada Inayah apakah ia merasa teraniaya atau tidak. Selain itu, Faris juga berharap menemukan jalan untuk melewati kesulitan dan meraih kebahagiannya.

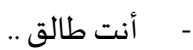

$$
\begin{aligned}
& \text { لم تستطيع أن تجد دموعها ، وأمسك بمفرش المنضيدة في قبضتيها المتشجتين وصهدر عنها أنين مكبوت ، فهتف: } \\
& \text { - وما جدوي الدموع ؟ لقد فات الأوان. } \\
& \text { وعاودتها نوبة كبرياء طعينة وقالت: } \\
& \text { ؛ }
\end{aligned}
$$

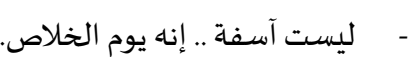

Kutipan tersebut menunjukkan Inayah sangat senang diceraikan oleh suaminya yang kejam tersebut, ia bahkan menangis bahagia dan merasa kebebasannya telah kembali. Itu bisa kita lihat pada jawaban Inayah "Sebenarnya hari itu adalah hari pembebasan".

Faris dan Inayah dalam menjalani hidupnya dipengaruhi oleh arketipe 'diri' berupa keinginan mereka terbebas dari kehidupan yang menyiksa mereka selama ini yaitu Faris tersiksa oleh kehidupan penjara sementara Inayah tersiksa oleh kehidupan rumah tangganya. Arketipe 'diri' mereka lah yang membuat mereka untuk bertindak untuk ceroboh dan melanggar norma agama dan sosial yaitu perzinahan. Perzinahan tersebut yang memberikan mereka kebebasan yang diinginkan tapi menanggung resiko yaitu Faris mati diracuni dan Inayah diceraikan dan kehormatannya hilang.

\section{Penutup}

Berdasarkan temuan penelitian dan pembahasan dapat disimpulkan bahwa perubahan prilaku tokoh Faris dan Inayah dalam novel lail wa Qudbhan karya Najib al-Kailani dipengaruhi oleh arketipe-arketipe ketaksadaran mereka. Adapun arketipe tokoh Faris yang muncul dalam novel tersebut terdiri atas persona ketegaran, bayangan mendorong membunuh dan perzinahan, anima

\footnotetext{
48 al-Kailani, hal. 44.

49 al-Kailani, hal. 177.
} 
emosional yang meluap berupa tangisan, ibu agung menghendaki balas dendam, orang tua bijak menasihati cara bertahan hidup, dan dirimenuju kebebasan hidup. Sementara arketipe-arketipe ketidaksadaran Inayah terdiri atas persona hidup yang bahagia, bayangan menyuarakan untuk membunuh Abdul Hadi dan melakukan perselingkuhan, animus berpikir rasional dan keras kepala, ibu agung yang mengasihi, orang tua bijak mengajarkan kesabaran, dan diri menuju kebebasan hidup.

Arketipe ketaksadaran Faris dan Inayah yang ditemukan dalam novel mengarahkan pada dua arah yaitu ada yang mengarahkan kepada prilaku positif dan ada yang mengarahkan kepada prilaku negatif. Perubahan prilaku tokoh Faris dan Inayah kepada prilaku buruk diakibatkan oleh ketidakmampuan mereka dalam menyaring dan menekan arketipe yang negatif. Kemudian arketipe positif mereka tidak mampu mendominasi dalam mengarahkan prilaku Faris dan Inayah ke Arah yang lebih baik. 


\section{Bibliografi}

Al-Arini, Abdullah bin Shalah. Al-Ittihah al-Islamy fii A'mal Najib al-Kailany alQasasiyyah. Riyadh: Dar Kunuz Isbiliya Linnasyri wa al-Tauzik, 2005.

Allen, Roger. Pengantar Kajian Novel Arab. Diterjemahkan oleh Erza. Yogyakarta: Era Baru Pressindo, 2012.

Alwisol, Alwisol. Psikologi Kepribadian. Malang: UMM Press, 2009.

Amanah, Tazkiyyatul. "Surah 'Inayat Hanim fii al-Riwayah Lail wa Qudbhan Li Najib al-Kailani (Dirasah Naqdiyyah Adabiyyah Nisaiyyah)." Skripsi, UIN Sunan Kalijaga, 2017. http://digilib.uin-suka.ac.id/28755/.

Ariyanti, Novi. "Kajian Sosiologi Sastra Pada Tokoh Utama Dalam Novel alRajul al-Ladzi Amana Karya Najib al-Kailani.” Arabiyatuna: Jurnal Bahasa Arab Vol. 3. No. 1 (Mei 2019).

Endraswara, Suwardi. Metode Penelitian Psikologi Sastra. Yogyakarta: Medpress, 2008.

. Metodologi Penelitian Sastra: Epistemologi, Model dan Aplikasi. Yogyakarta: Medpress, 2008.

Feist, Jess, Gregory J. Feist, dan Tomi-Ann Roberts. Teori Kepribadian. Diterjemahkan oleh R. A. Hadwitia Dewi Pertiwi. 8 ed. Vol. 1. 2 vol. Jakarta: Salemba Humanika, 2017.

Hailiyati, Nia. "Perbandingan Ideologi Pada Novel 'Azra' Jakarta Dengan Imagologie Sejarah G30s-Pki Versi Perpustakaan Nasional.” Tsaqofah \& Tarikh 4, no. 1 (Juni 2019): 78-87.

Hall, Calvin S., dan Gardner Lindzey. Psikologi Kepribadian 1: Teori-Teori Psikodinamik (Klinis). Disunting oleh A. Supratik. Yogyakarta: Kanisius, 2005.

Hikmat, Mahi M. Metode Penelitian: Dalam Perspektif Ilmu Komunikasi dan Sastra. Yogyakarta: Graha Ilmu, 2011.

Jung, Carl Gustav. Manusia dan Simbol-Simbol: Simbolisme dalam Agama, Mimpi, \& Mitos. Diterjemahkan oleh Siska Nurrohmah. Yogyakarta: Basabasi, 2018.

Memories, Dreams, Reflections: Memori, Mimpi, Refleksi. Diterjemahkan oleh Apri Danarto dan Ekandari Sulistyaningsih. Yogyakarta: Jendela, 2003.

. Psikologi dan Agama. Diterjemahkan oleh Afthonul Afif. Yogyakarta: IRCisoD, 2017.

. The Spirit in Man, Art, and Literature: Betapa Dabsyatnya Spirit Manusia.

Diterjemahkan oleh Cep KM Subhan. Yogyakarta: IRCisoD, 2019. 
Kailani, Najib al-. Lail wa Qudbhan. Kairo: Al-Sahoh, 2013.

—. Tajribati al-Dzati fii Qissah al-Islamiyyah. Kairo: Al-Sahoh, 2015.

Mukramatun. "al-Shira'u al-Nafsi fii Riwayah 'Lail wa Qudbhan' Linajib alKailani (Dirasah Shikulujiyyah)." Skripsi, UIN Ar- Raniry, 2018. http://library.ar-raniry.ac.id.

Ratna, Nyoman Kutha. Teori, Metode, dan Teknik Peneitian Sastra. Yogyakarta: Pustaka Pelajar, 2015.

Rokhmansyah, Alfian. Studi dan Pengkajian Sastra. Yogyakarta: Graha Ilmu, 2014.

Samti, Muhammad Mahdi, dan Samanah Naqwi. "al-Madhamin al-Ijtima’iyyah fi Riwayah Lail wa Qudbhan Li Najib al-Kailani." Majallah Bubus fi alLughab al-Arabiyyah wa Adabiha: Nisfu Sanawiyyah 'Alamiyyab Mubkamah li Kulliyyah al-Lughah al-Ajnabiyyah bi Jami'ah Isfahan Volume 7 (Musim Gugur dan Musim Semi H/1433-1434 H 1391): 93-112. 